\title{
The Calcium-Sensing Receptor as a Regulator of Cellular Fate in Normal and Pathological Conditions
}

\author{
A. Diez-Fraile", T. Lammens ${ }^{2}$, Y. Benoit ${ }^{2}$ and K.G.M.A. D'Herde ${ }^{*}, 1$ \\ ${ }^{1}$ Department of Basic Medical Sciences, Ghent University, Faculty of Medicine and Health Sciences, 9000 \\ Ghent, Belgium \\ ${ }^{2}$ Department of Pediatric Hematology-Oncology, Ghent University Hospital, 9000 Ghent, Belgium
}

\begin{abstract}
The calcium-sensing receptor (CaSR) belongs to the evolutionarily conserved family of plasma membrane G protein-coupled receptors (GPCRs). Early studies identified an essential role for the CaSR in systemic calcium homeostasis through its ability to sense small changes in circulating calcium concentration and to couple this information to intracellular signaling pathways that influence parathyroid hormone secretion. However, the presence of CaSR protein in tissues is not directly involved in regulating mineral ion homeostasis points to a role for the CaSR in other cellular functions including the control of cellular proliferation, differentiation and apoptosis. This position at the crossroads of cellular fate designates the CaSR as an interesting study subject is likely to be involved in a variety of previously unconsidered human pathologies, including cancer, atherosclerosis and Alzheimer's disease. Here, we will review the recent discoveries regarding the relevance of CaSR signaling in development and disease. Furthermore, we will discuss the rational for developing and using CaSR-based therapeutics.
\end{abstract}

Keywords: Apoptosis, calcium-sensing receptor, differentiation, proliferation, signaling, cancer.

\section{INTRODUCTION}

Brown and colleagues identified and cloned the calcium-sensing receptor (CaSR, also called GPRC2A) from bovine parathyroid cells in their quest to identify the calcium-sensing molecule responsible for coupling extracellular calcium concentration to parathyroid hormone (PTH) secretion [1]. The CaSR is an evolutionarily conserved $G$ protein-coupled receptor (GPCR) highly expressed in tissues involved in systemic calcium homeostasis, including the parathyroid gland, calcitonin-secreting $\mathrm{C}$ cells of the thyroid gland, kidney, bone and gastrointestinal tract [2], where it contributes to maintenance of systemic calcium within a narrow physiological window. Activation of the parathyroid gland CaSR by increased levels of extracellular calcium suppresses PTH secretion, resulting in increased renal calcium excretion and decreased calcium resorption from bone tissue. In kidneys, CaSR activation can directly enhance urinary calcium excretion by inhibiting distal tubular calcium reabsorption, and in C cells, CaSR activation stimulates the release of calcitonin, inhibiting bone resorption and stimulating renal calcium excretion.

Recently, the CaSR was found to be widely expressed in cells and tissues not directly involved in systemic calcium homeostasis, as well. Not surprisingly, the CaSR works pleiotropically at multiple

\footnotetext{
*Address correspondence to this author at the Department of Basic Medical Sciences, Campus Heymans 4B3, De Pintelaan 185, Ghent University, Faculty of Medicine and Health Sciences, 9000 Ghent, Belgium; Tel: +32 9 3325192; Fax: +32 9 3323809;

E-mail: Katharina.Dherde@UGent.be
}

levels, regulating diverse processes such as hormone secretion, gene expression, ion channel activity, inflammation, and control of cellular fate. Here, we will review the recent findings regarding the physiological effects of CaSR activity on the regulation of cellular fate, particularly in the context of proliferation, differentiation and apoptosis [2-10]. We will discuss how CaSR signaling determines cellular fate during normal development and how dysregulated signaling might promote the pathogenesis of many diseases, ranging from proliferative to neurodegenerative and vascular diseases.

\section{STRUCTURAL FEATURES}

The CaSR is a member of a unique subfamily (known as family 3 or family C) of GPCRs which includes eight subtypes of metabotropic glutamate receptors (mGluR18), two type $B y$-aminobutyric acid receptors $\left(G A B A_{B} R s\right)$, the promiscuous $L-\alpha$-amino acid receptor GPRC6A, three taste receptors, several pheromone receptors, and five orphan receptors [11]. The human CaSR gene is located on chromosome $3 \mathrm{q} 13.3-21$ and spans over $50 \mathrm{~kb}$ of genomic DNA. Its cDNA sequence predicts a $120-\mathrm{kDa}$ protein, harbouring seven transmembrane (7TM)-spanning alpha-helices, a characteristic feature of all GPCRs. Other structural features include a large extracellular domain (ECD) in the $\mathrm{N}$-terminal portion of the receptor defined by a Venus flytrap (VFT) module and a cysteinerich domain, and an intracellular carboxyl terminal tail with consensus regulatory phosphorylation sites for protein kinase C (PKC) and protein kinase A [12]. Apart from phosphorylation, the CaSR can undergo several other post-translational modifications including intermolecular disulphide homodimerization and glycosylation of its 
extracellular domain, evidenced by 11 potential $\mathrm{N}$ glycosylation sites in its extracellular $\mathrm{N}$-terminus [13]. Several observations show that these modifications might be essential for CaSR expression and/or function. Specifically, glycosylation and dimerization appear to be essential for proper folding and trafficking of the CaSR protein, eventually regulating the membrane expression of the CaSR. Moreover, an altered CaSR glycosylation pattern has been observed in some forms of familial hypocalciuric hypercalcemia $(\mathrm{FHH})[14]$.

\section{REGULATION OF CASR EXPRESSION}

\subsection{Transcriptional Regulation}

During recent years, it has become clear that CaSR expression depends on the cell or organ type, developmental state and even extracellular conditions. Although the promoter and untranslated regions of the CaSR have been characterized, only a few regulatory regions have been linked to the varied expression. Suzuki et al. characterized the presence of a thyroid transcription factor 1 (TTF1)-binding site in the 5' flanking region of the CaSR, and found that TTF1 directly regulates CaSR transcription in cell types co-expressing TTF1 and CaSR (this includes parathyroid cells, neural cells in the anterior pituitary or hippocampus, and keratinocytes, but excludes cells such as buffalo rat liver cells) [15]. However, the authors demonstrated that this regulation might be more complicated than anticipated since TTF1 levels depend on internal calcium concentration, as well [15]. Further analysis of potential transcription factor (TF)-binding sites within the proposed CaSR promoter indicates the presence of two binding regions for EBF1 and one binding region each for NF-KB, BATF, C-Jun, BAF-155, FOSL2 and BCL11A (Fig. 1). The well-established role of these TFs in regulating cellular fate establishes the transcriptional platform for the involvement of CaSR signaling in regulating proliferation, differentiation and apoptosis. Thus, it will be of great interest to assess whether one or several of these TFs regulate CaSR mRNA levels.

Several vitamin $D$ response elements have been identified in the CaSR promoter, as well (Fig. 1). A study by Abukawa et al. revealed that the vitamin Ddependent regulation of CaSR expression is tissuespecific [16]. In this study, the authors showed that vitamin $D$ positively regulates CaSR transcript levels in rat kidney but does not affect CaSR mRNA expression levels in intestine or calvaria. However, whether this differential expression correlated with a loss of vitamin D-responsive elements, which is suggested by the different transcript lengths observed in the respective tissues, remains to be determined [16].

\subsection{Splice Variants}

In addition to differential TF-binding, an extra level of gene regulation is generated by differential splicing. Oda et al. identified the presence of an exon-5-less CaSR transcript in human keratinocytes and made two crucial observations related to CaSR function [17]. First, they observed that the splice variant possesses an altered glycosylation pattern and is unable to mediate the acute response to extracellular calcium in keratinocytes. Second, they found that the full-length CaSR transcript is expressed predominantly in undifferentiated keratinocytes, and expression levels decrease as the cells differentiate. In contrast, the exon-5-less splice variant transcript is expressed throughout keratinocyte differentiation [17]. Thus, the expression of a CaSR splice variant that does not respond to calcium points to additional functions of the CaSR outside of calcium homeostasis. This exon-5less transcript has been found in the growth plate and kidney of mice [18, 19], as well, and an exon-3-less transcript has been reported to be expressed in cytotrophoblasts of human placenta [20]. This exon-3less splice variant encodes a truncated protein of 153 amino acids, which would not be incorporated into the plasma membrane. As described for truncated forms of other receptors, it might be released into the extracellular fluid (circulation), but to the best of our knowledge nobody has reported on the functional significance of this [20,21].

Wang et al. have shown that rat dorsal root ganglion neurons express a CaSR transcript that differs from the classical transcript (which they define as being expressed in the thyro-parathyroid and kidney) in the 5' untranslated region (5'UTR) due to splicing of alternative exons into a common coding region [22]. This fits the earlier observation of this variant in the human system by Chikatsu and colleagues [23]. It is well-established that the 5'UTR contains elements that regulate the stability and translation of the corresponding transcript, but the impact of this alternatively spliced 5'UTR on CaSR expression has not been assessed.

\subsection{MicroRNAs}

Small non-coding microRNAs (miRNAs) emerged recently as novel regulators of gene expression. MicroRNAs function through complementary basepairing with target mRNAs, subsequently leading to the inhibition of translation or to degradation of the mRNA target. MicroRNAs have been shown to be involved in virtually all cellular processes and are frequently dysregulated in disease states including cancer. Although several miRNAs are predicted to bind the CaSR mRNA and potentially regulate CaSR expression (our unpublished observations), to our best knowledge, none has been confirmed to regulate CaSR (Fig. 1).

Several post-transcriptional mechanisms, including ubiquitination, homodimerization and m-calpaindependent destruction, regulate CaSR protein levels, as well, and these will be discussed in more detail in 'Signaling and binding partners' below.

\section{SIGNALING AND BINDING PARTNERS}

\subsection{Positive and Negative Modulators}

In contrast to what its name suggests, the CaSR has a broad spectrum of ligands, including its namesake calcium. Agents altering CaSR signaling are 


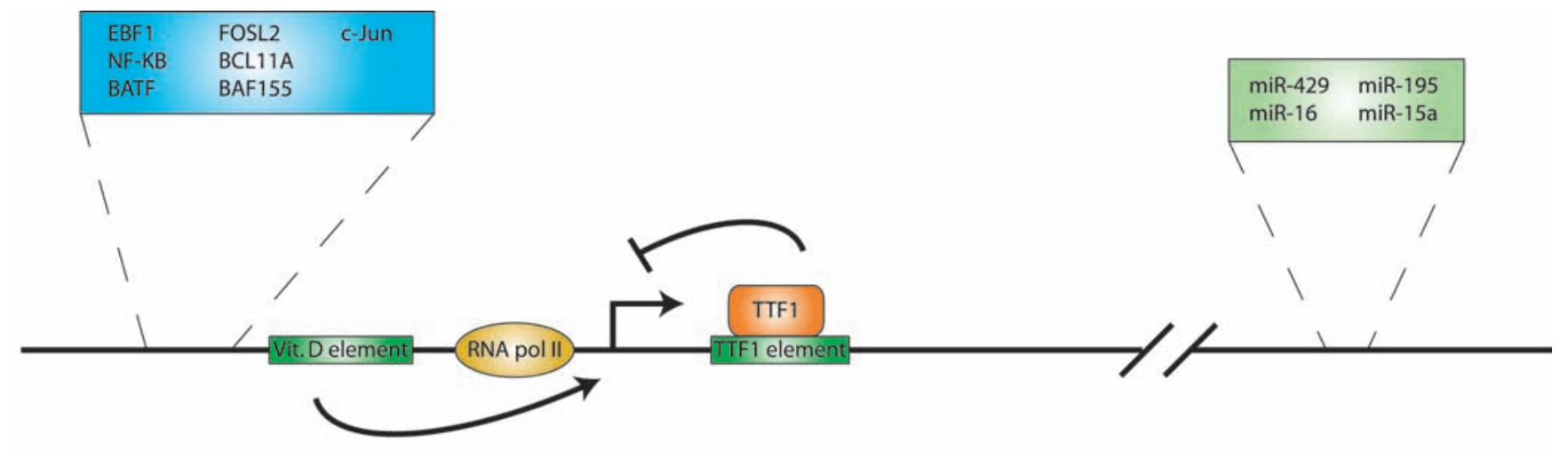

Fig. (1). Regulation of CaSR expression. TTF1 and vitamin D binding elements (green boxes) have been well-characterized in the 5' flanking region and promoter, respectively, of CaSR. Potential transcription factor-binding sites, as reported in the UCSC genome browser (http://genome.ucsc.edu/) are depicted as well (blue box). Possible miRNA - CaSR mRNA interactions were determined using miRDB, miRanda and Targetscan prediction software, and the intersection is represented in the green box. miR: microRNA: RNA pol II: RNA polymerase II.

generally divided into positive or negative modulators and orthosteric or allosteric ligands (which refers to the site of interaction). As such, we recognize orthosteric modulators, positive allosteric modulators and negative allosteric modulators (Fig. 2). Orthosteric modulators of the CaSR include calcium and other di- and trivalent cations $\left(\mathrm{Be}^{2+}, \mathrm{Sr}^{2+}, \mathrm{Mg}^{2+}, \mathrm{Gd}^{3+}, \mathrm{La}^{3+}, \mathrm{Ba}^{2+}\right)$ that bind at the orthosteric site within the VFT module. In addition, polyamines, such as spermine, spermidine and putrescine, aminoglycoside antibiotics such as neomycin, and $\beta$-amyloid peptides have been found to bind the orthosteric site [24-26]. In contrast, allosteric modulators bind outside of the orthosteric site, most likely changing the three-dimensional receptor conformation and, thus, affecting the receptor affinity and/or ligand-binding efficacy. Well-known natural allosteric activators include L-amino acids, which bind adjacent to the orthosteric site within the VFT module [27-29]. This ability of amino acids to regulate CaSR activation suggests the existence of a close link between calcium signaling and nutritional status. In recent years, several pharmacological agents that positively modulate CaSR signaling (calcimimetics) or negatively modulate CaSR signaling (calcilytics) have been developed. Both types of modulators bind the 7TM extracellular loops of the CaSR [30]. These will be discussed in more detail in the section entitled "CaSR as a therapeutic target".

\subsection{Receptor Dimerization}

It is now well-accepted that the CaSR functions primarily as a homodimer supported by both covalent and non-covalent interactions [31]. Dimerization of the CaSR seems essential, but not sufficient, for membrane trafficking, and crucial for correct function $[32,33]$. Besides homodimerization, the CaSR also forms heterodimers with other members of family $\mathrm{C}$ of the GPCR superfamily, such as mGluRs and $\mathrm{GABA}_{\mathrm{B}} \mathrm{Rs}$. Co-immunoprecipitation experiments revealed direct interactions of the CaSR with the mGluR1 $\alpha, G_{B B A} R_{1}$ and $G A B A_{B} R_{2}$ in certain regions of bovine and rat brains [34, 35]. These interactions have been shown to be determinative for both total cellular and cell surface expression of CaSR and the activation status of phospholipase C (PLC) [35]. Remarkably, while coexpression of the CaSR with $\mathrm{GABA}_{\mathrm{B}} \mathrm{R}_{1}$ reduced CaSR-dependent PLC activation, coexpression with $\mathrm{GABA}_{B} \mathrm{R}_{2}$ increased agonistdependent PLC activation [35].

In addition to direct interactions with other receptors, several research groups have demonstrated communication between the CaSR and the epidermal growth factor receptor (EGFR) [3, 36, 37]. Using a combination of inhibitors and neutralizing antibodies, Yano et al. showed that phosphorylation of extracellular signal-regulated kinase (ERK), a key target of CaSR signaling, could be abrogated by inhibiting the EGFR or the production of EGF through matrix metalloproteases in HEK293 cells stably expressing the CaSR (Fig. 2) [36]. Importantly, Haini and colleagues recently demonstrated the critical role of this CaSR-EGFR-ERK axis in the delivery of mitogenic signals in MCF7 breast cancer cells. Considering the function of EGFR in stimulating DNA synthesis and cell proliferation, this relationship connects the CaSR to determination of cell fate [37].

\subsection{Protein Binding Partners}

Recent reports demonstrate the interaction of CaSR with several other proteins. Using the intracellular tail of the CaSR as the bait in yeast two-hybrid screens, two groups independently identified the scaffold protein, filamin A, as a CaSR-binding partner. Such interactions with filamin $A$ are believed to modulate the rates of 
A

\begin{tabular}{|c|c|c|}
\hline $\begin{array}{c}\text { Orthosteric } \\
\text { modulators }\end{array}$ & $\begin{array}{c}\text { Positive allosteric } \\
\text { modulators } \\
\mathrm{Ca}^{2+}\end{array}$ & $\begin{array}{c}\text { Negative allosteric } \\
\text { modulators }\end{array}$ \\
$\begin{array}{c}\text { Other cations }\left(\mathrm{Gd}^{3+}, \mathrm{Mg}^{2+}\right) \\
\text { Polyamines }\end{array}$ & L-Amino acids \\
$\begin{array}{c}\text { Aminoglycoside antibiotics } \\
\text { Amyloid-beta peptides }\end{array}$ & Calcimimetics & \\
\hline
\end{tabular}

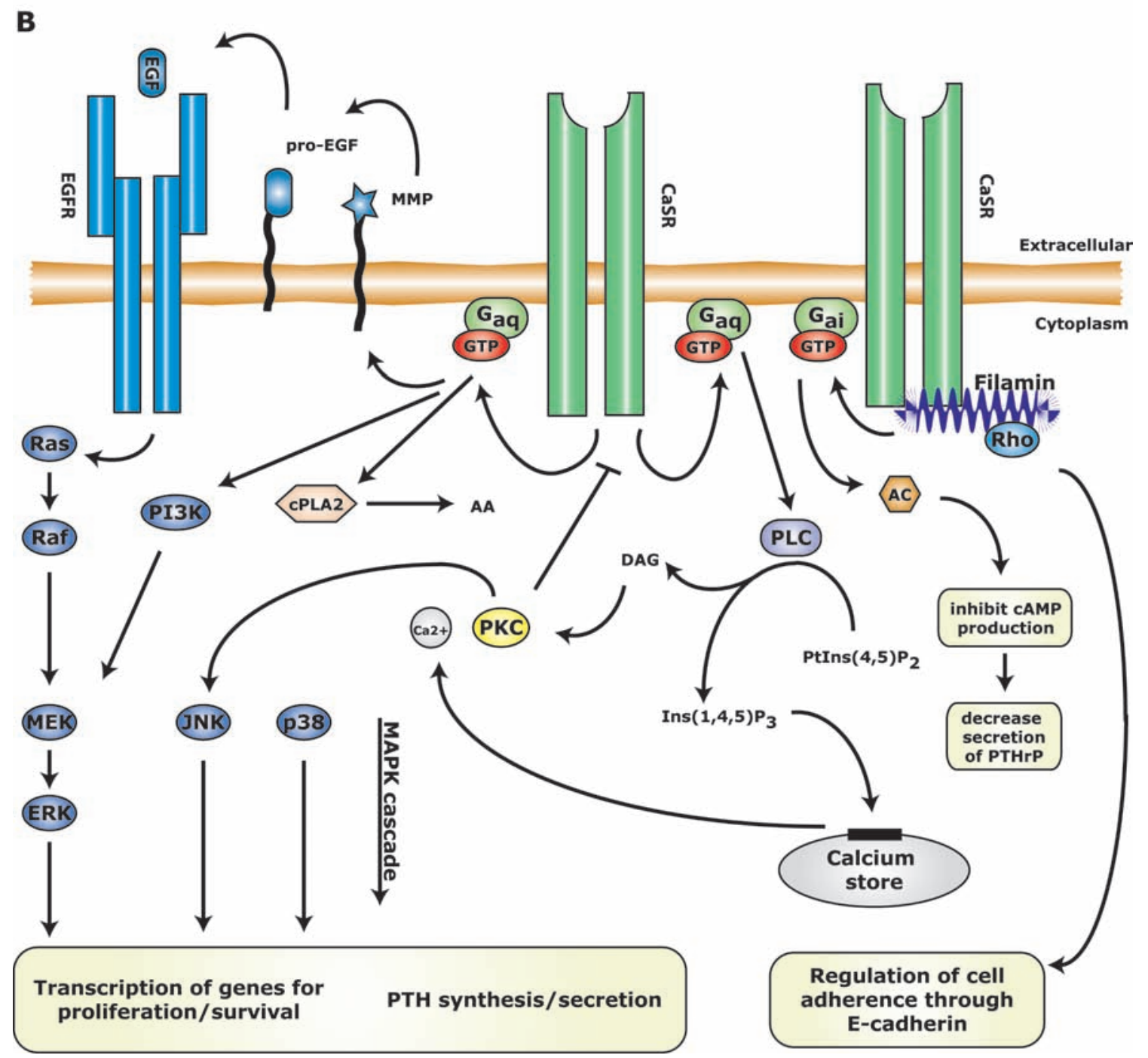

Fig. (2). Schematic diagram of CaSR signaling and interaction partners. A. CaSR interaction partners are commonly categorized as orthosteric modulators, positive allosteric modulators or negative allosteric modulators. $\mathbf{B}$. The CaSR is present on the cell membrane as a homo- or heterodimer, and affects the signaling of other receptors such as EGFR (shown here; see text for other CaSR partners). The signaling cascades initiated by the CaSR include (but are not limited to): $\mathrm{G}_{\mathrm{ai}}$-dependent inhibition of adenylate cyclase (AC), reducing cyclic AMP (CAMP) production; interaction with filamin $A$ and Rho, regulating cell adherence through E-cadherin; $G_{\mathrm{dq}}$-dependent activation of cytosolic phospholipase A2 (cPLA2), causing the accumulation of arachidonic acid (AA); $G_{a q}$-mediated activation of phospholipase $C(P L C)$, activating protein kinase $C(P K C)$ through diacylglycerol (DAG) and the release of calcium from the endoplasmic reticulum through inositol 1,4,5-trisphosphate (IP3); activation of mitogen-activated protein kinases (MAPK) such as JNK and p38; and $\mathrm{G}_{\mathrm{qq}}$-dependent activation of epidermal growth factor (EGF)-signaling, resulting the activation of the Ras-Raf-MEK-ERK signaling cascade. The complex array of CaSRregulated pathways ultimately result in the regulation of gene transcription for proliferation and survival, regulation of parathyroid hormone (PTH) secretion and synthesis, regulation of parathyroid hormone-related protein (PTHrP) secretion and the regulation of cell adherence through E-cadherin. 
receptor desensitization and degradation. Notably, inhibition of CaSR expression with antisense cDNA 48 hours after transfection with or without filamin A resulted in a lower level of CaSR expression in cells without filamin A, suggesting that filamin A protects the CaSR from degradation [38]. Several other groups have provided evidence that the interaction with filamin $A$ is, at least partially, involved in the CaSR-dependent activation of downstream mitogen-activated protein kinases (MAPKs) and Rho, a Ras-like family member involved in many cellular functions including proliferation (Fig. 2) [39, 40].

In addition to filamin $A$, the potassium channel Kir4.2 was identified as a potential CaSR-binding partner. Given the interaction of Kir2.1 with filamin A, the authors postulated that filamin A might act as a scaffold, bringing the CaSR and Kir4.2 together [41]. With the addition of Dorfin to the list of CaSR-binding partners, it became clear that the CaSR protein levels are, at least partially, regulated through a general mechanism of poly-ubiquitination [42]. Kifor and colleagues identified the CaSR protein to be sensitive for m-calpain-dependent destruction, as well, adding an additional mechanism for regulating CaSR protein expression [43].

\subsection{Intracellular Signaling}

The intracellular signaling of CaSR has been the subject of intense investigation (Fig. 2). Reports using overexpression, knock-down or pharmacological inhibition or stimulation of CaSR signaling have provided clear evidence for a role of CaSR in finetuning proliferation, differentiation and apoptosis. As is the case with many other cell-surface receptors, at present, it is only poorly understood how the activation of a single receptor type, in this case the CaSR, can result in such varied biological endpoints.

Generally, ligand binding to the CaSR results in the activation of PLC in a $G_{\alpha q}$-mediated manner ( $G_{\alpha q}$ : subunit of heterotrimeric $G$ protein). Subsequently, PLC propagates this signal using multiple signaling pathways (Fig. 2). The accumulation of inositol 1,4,5trisphosphate (IP3) and diacylglycerol (DAG) observed upon CaSR stimulation was shown to depend on PLC activation, since this IP3 response could be blocked by the PLC inhibitor U-73122 [44]. In turn, IP3 induces the release of intracellular calcium from the endoplasmic reticulum, resulting the activation of cytosolic phospholipase A2 (cPLA2) and the generation of second messengers such as arachidonic acid (Fig. 2). In kidney, this CPLA2 signaling axis mediates the effects of hypercalcemia (see: CaSR in development).

The release of DAG, in addition to the increased cytoplasmic calcium concentration, activates PKC (Fig. 2) $[45,46]$. Activated PKC serves as an input signal for MAPK cascades, controlling cell proliferation and apoptosis. Using inhibitor studies, Kifor et al. demonstrated that activation of PKC in the CaSR-PLC axis results in phosphorylation (activation) of ERKs through MAPK kinases (MEKs) [47]. Almost simultaneously, Hobson and colleagues identified two additional pathways through which CaSR activation stimulates ERK phosphorylation. In an elegant study using rat ovarian epithelial cells as a model, Hobson and colleagues identified the CaSR-Src-Ras-Raf-MEKERK pathway as a CaSR-driven alternative path to ERK activation (Fig. 2) [48]. Later, the same authors implicated phosphatidylinositol 3-kinase (PI3K) in CaSR-dependent ERK activation, driven by the observation that only low levels of ERK activation were detected after treatment of CaSR-stimulated ovarian epithelial cells with PI3K inhibitors. Importantly, in this study, they observed that ERK activation can be blocked by tyrosine kinase inhibitors in Rat-1 fibroblasts, whereas this was not the case in CaSRtransfected HEK293 cells. Although in vitro, this work illustrates that, at least to some extent, the specific CaSR downstream signaling pathways are cell-type specific, explaining the differential readouts in various cell types examined [49]. Further studies have implicated JNK and p38 MAPK in CaSR-stimulated pathways involved in proliferation and apoptosis, as well (Fig. 2) [50-52].

Generally, the activation of MAPK cascades serves to control cell survival and proliferation through multiple distal effectors. Indeed, in many instances, activation of the CaSR results in the transcription of mRNA for Fos, Egr-1 and cyclin-D [53], all of which help promote the G1/S cell cycle transition [53]. Several reports witness that CaSR-mediated apoptosis, through mechanisms related with calcium overload and activation of the mitochondrial apoptotic pathways, involves the downregulation of $\mathrm{Bcl}-2$ expression, and upregulation of caspase-3, cytochrome $\mathrm{c}$ and Fas/FasL expression [54-59]. Importantly, Mentaverri et al. reported that NF$\mathrm{KB}$ activation, which promotes expression of cell death genes such as p53, c-Myc and Bcl-xS, is a downstream effect of CaSR stimulation in mature rabbit osteoclasts [60]. Phosphorylation of ERK regulates cell growth and differentiation through phosphorylation and activation of nuclear TFs, such as Elk-1. In agreement with these downstream effects, stimulation of the CaSR in many model systems, including smooth muscle cells, epithelial cells and granulosa cells, results in an increased cell number and/or increased survival $[5,10$, 49, 53, 61]. Finally, CaSR signaling also has been implicated in regulating colonic epithelial cell differentiation and keratinocyte differentiation through the activation of E-cadherin signaling in a Rhodependent manner with filamin A involvement (Fig. 2) [62-64]. Chakrabarty and colleagues demonstrated that stimulation of the CaSR through extracellular calcium increased the expression of the tumor suppressor on colon carcinoma cells, and concomitantly reduced the activation of $\beta$-catenin/T-cell factor, leading to the suppression of their malignant behavior [63]. They concluded that, consequently, the integrity of the CaSR-E-cadherin- $\beta$-catenin axis may be important in maintaining correct colon epithelial cell differentiation [63]. In addition, keratinocyte differentiation has been shown to depend on the physical interaction between the CaSR, filamin A and Rho. Moreover, the Rho- 
filamin axis would drive a diverse array of kinase activities [64, 65].

In addition to this already highly complex signaling network, calcium-stimulation of the CaSR downregulates cellular cyclic AMP (cAMP) levels through adenylate cyclase (AC) in a $\mathrm{G}_{\mathrm{ai}}$-dependent mechanism [66]. Lower levels of cAMP eventually result in decreased secretion of the $\mathrm{PTH}$-related protein (PTHrP), which, among others, is involved in bone and teeth development [66]. Interestingly, Mamillapalli and colleagues have provided evidence that the alternative use of the $G_{a s}$ subunit stimulates $A C$ activity and, thus, cAMP production [67].

\section{DIFFERENTIAL TISSUE EXPRESSION AND REGULATION OF CELLULAR FATE}

\subsection{Fetal Development}

The CaSR is highly expressed in the developing fetus, with the highest expression levels found in the central and peripheral nervous system, heart, lung and cartilage [68]. The developing fetus is hypercalcemic compared with the adult, with significantly higher levels of extracellular calcium found in cord blood as compared with maternal blood [69]. The elevated levels of extracellular calcium in the fetus appear necessary for proper fetal growth and development. Indeed, activation of the CaSR by high extracellular calcium or a calcimimetic was shown to promote axonal growth in murine fetal sympathetic neurons during the perinatal period. In addition, the CaSR plays a crucial role in the elaboration of normal dendritic arbors in pyramidal neurons during early postnatal development of the mouse hippocampus [70]. Regarding the developing mouse lung, Finney and colleagues demonstrated that, between embryonic days 10.5 and 16.5, calcium concentrations similar to those encountered in developing fetuses $(\sim 1.7 \mathrm{mM})$ inhibit lung branching morphogenesis and cellular proliferation while promoting lung fluid secretion via activation of the CaSR [71]. After embryonic day 16.5, CaSR expression progressively diminishes and is absent in adult lung tissue [1, 71, 72]. By means of tissuespecific deletion of the CaSR, it was evidenced that CaSR expression is crucial for the proper fetal bone development and mineralization [73]. The CaSR is also expressed in fetal embryonic tissue of the placenta throughout pregnancy. It has been proposed that, in addition to the local control of transplacental calcium [74], the CaSR might contribute to the regulation of placental development, as well $[75,76]$.

\subsection{Adult}

In the adult, CaSR expression has been detected in a myriad of cells and tissues. By means of a short expression survey using Genevestigator (www.genevestigator.com), we confirm expression of the CaSR gene in a broad array of human adult tissues with varying degrees of abundance (Fig. 3). Expression of CaSR protein has been detected and implicated in regulating cellular fate in adult tissues including the parathyroid gland, bone, kidney and blood, as well as reproductive, cardiovascular, gastrointestinal and skin tissue.

The parathyroid gland expresses the highest levels of CaSR and CaSR activity within parathyroid cells may regulate cell survival [77]. Calcimimetic-treated uremic rats were shown to have smaller parathyroid glands, and increased apoptosis was observed in parathyroid cells in vitro [78]. However, two other reports using the same rat model did not detect an increase in the number of apoptotic parathyroid cells $[79,80]$. The fast clearance of apoptotic cells by macrophages in vivo may hamper the visualization of dying cells and might explain this apparent contradiction.

Pronounced expression of the CaSR is also detected in the cardiovascular system, especially in heart tissue (Fig. 3). Activation of the CaSR can induce apoptosis in normal rat neonatal cardiomyocytes [54, 81] and in cultured neonatal rat ventricular cardiomyocytes exposed to ischemia/reperfusion [55, 82-84]. In addition, stimulation of CaSR with extracellular calcium in human aortic vascular smooth muscle cells has been shown to lead to cell proliferation and protection against apoptosis [5].

Similarly, activation of CaSR in cultured osteoblasts treated with elevated concentrations of extracellular calcium not only promoted the proliferation of these cells but also stimulated cell differentiation and mineralization within bone tissue [53]. In the rat kidney, the calcimimetic R-568 exerts a direct nephroprotective action at the glomerular podocyte level, since this pharmacological activation of the CaSR limited podocyte damage through stimulation of anti-apoptotic and cytoskeleton-stabilizing mechanisms [85]. Pharmacologic modulation of the CaSR by cinacalcet, a positive allosteric modulator, enhances primitive hematopoietic cell activity in vitro, including growth in stromal cell cocultures [86].

Within the human female reproductive tract, ovarian surface epithelial cells have been shown to express the CaSR [48]. Using immortalized ovarian surface epithelial cells, it was shown that the presence of increased extracellular calcium or the expression of a dominant negative mutant of the CaSR stimulates proliferation. The increased extracellular calcium concentration within this experimental setup mimics the higher local concentrations of calcium at the ovarian surface found upon ovulation. Thus, these results indicate that the CaSR might be involved in healing of the ruptured ovarian surface epithelium during ovulation $[48,87]$. Before conception, the CaSR may play a role in oocyte meiotic maturation. Incubation of horse oocytes in the presence of calcium in combination with the calcimimetic R-467 results in significantly increased numbers of oocytes in metaphase II, and this is attenuated by pre-treatment with the CaSR antagonist NPS-2390 [88]. Furthermore, the CaSR is not only expressed in the germ line, but also in the surrounding somatic cells where activation has been proposed to play a role in follicle survival [10]. 


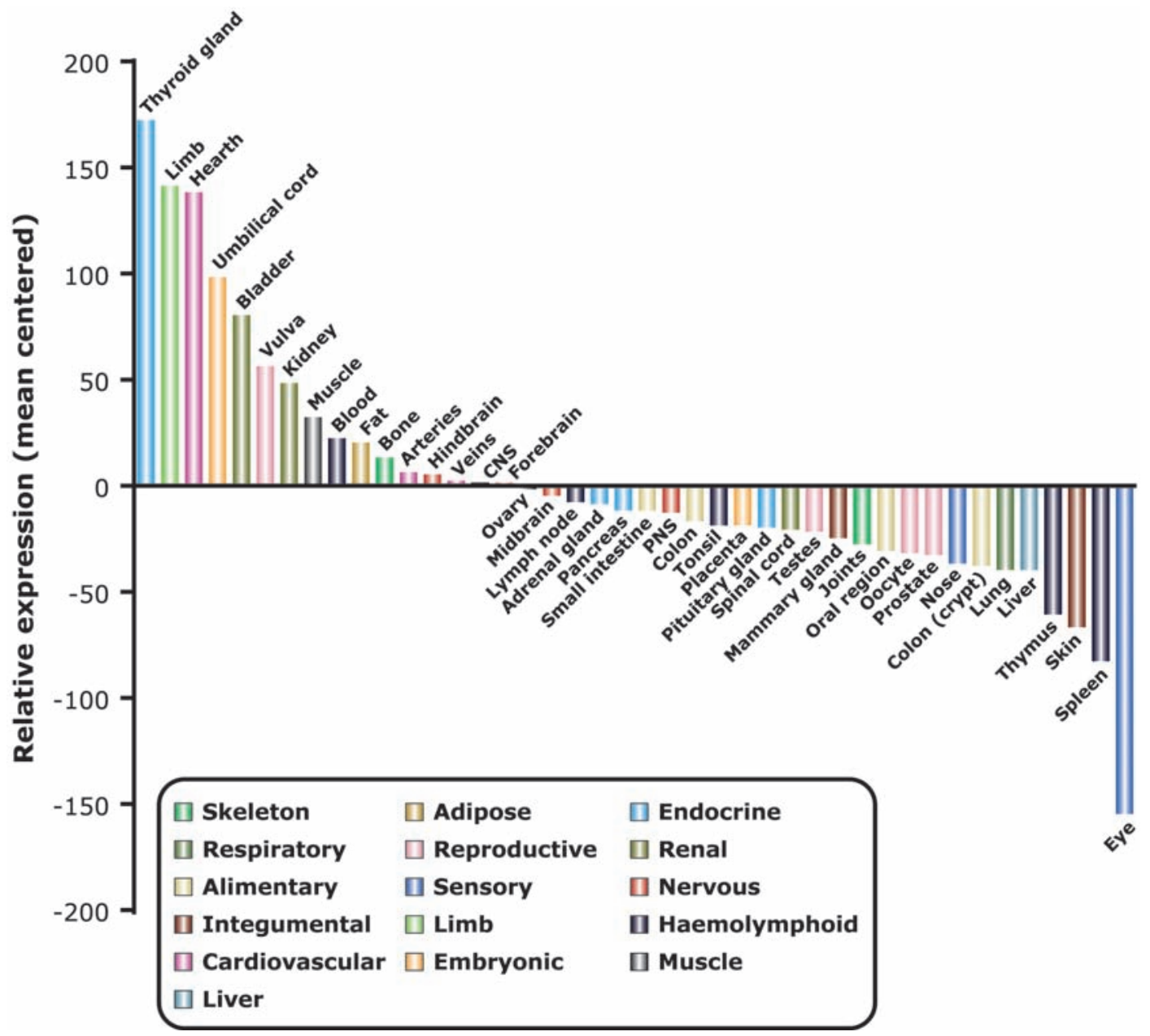

Fig. (3). Relative CaSR expression levels in different organs/tissues. Normalized expression data were obtained through Genevestigator (http://www.genevestigator.com). Obtained values were mean centered and ranked from high to low expression. CNS: central nervous system; PNS: peripheral nervous system.

The CaSR is also widely expressed along the mammalian gastrointestinal tract including stomach, small intestine, and colonic mucosal epithelia, along with the underlying neural plexuses of Meissner and Auerbach [89]. In the intestine, although the relative expression of CaSR in colonic cells is below the mean (Fig. 3), studies carried out during the last decade have demonstrated that a functional CaSR is involved in the regulation of many aspects of colonic function, including the maintenance of epithelial proliferation, differentiation and development [89].

A similar role has been described in skin epithelial cells, where activation of the CaSR has been reported to enhance cell differentiation and integrity in both mouse and human keratinocytes. In vitro, keratinocytes are extremely sensitive to variations in extracellular calcium, with low extracellular calcium promoting proliferation and extracellular calcium concentrations above $0.1 \mathrm{mM}$ promoting differentiation [90, 91]. In agreement, Tu and colleagues have demonstrated that, in epidermal keratinocytes, CaSR activation by extracellular calcium and calcimimetics suppresses proliferation and increases the expression of genes involved in differentiation [92]. In vivo, the epidermis of full-length CaSR knock-out mice is thinner, abnormally flattened and less differentiated than that of wild-type animals [19]. In contrast, CaSR overexpression in the epidermis stimulates hair follicle formation and enhances epithelial integrity and the expression of differentiation markers [19, 92].

In summary, several fetal tissues show a transient increase in CaSR expression within a precise developmental time window, during which CaSR has been suggested to contribute to cell differentiation and survival. In addition, activation of the extracellular CaSR in adults drives cellular fate by either inhibiting or stimulating proliferation, differentiation or apoptosis, depending on the tissue or cell type.

\section{CaSR IN HUMAN DISEASES}

The identification of CaSR mutations fueled research into the involvement of the CaSR in human disease. To date, a massive repertoire of $257 \mathrm{CaSR}$ mutations has been characterized (listen on http://www.casrdb.mcgill.ca/). The spectrum of mutations is diverse and includes large aberrations such as insertions and deletions, as well as smaller aberrations such as point mutations that create novel 
splice sites, premature stop codons and single aminoacid changes [93]. Furthermore, single nucleotide polymorphisms (SNPs) have been described [94-96]. None of the SNPs appears to cause disease directly, but rather to enhance predisposition to disease. In addition to sequence changes, autoantibodies against the CaSR have been detected in patients [97, 98]. Below, we will review the involvement of CaSR in cancer, Alzheimer's disease and atherosclerosis.

\subsection{Cancer}

Since the CaSR is involved in balancing cell proliferation and apoptosis in many tissues, it is no surprise that dysregulation of the CaSR might favor progression to cancer. CaSR signaling has now been implicated in the development of several cancer types, including colon cancer, prostate cancer, breast cancer and lung cancer [99]. Whether the CaSR behaves as an oncogene or a tumor suppressor seems dependent on the tissue involved and/or the stage of disease (i.e. metastatic involvement).

The involvement of CaSR in colorectal cancer has been studied extensively. In healthy colon, a calcium concentration gradient is maintained within the colonic crypts, with the highest concentrations found towards the luminal end of the crypt where cells undergo terminal differentiation and, ultimately, apoptosis, and the lowest levels found at the base of the crypts where cells actively divide [100]. CaSR expression is reduced or absent in many colon cancers, leading to uncontrolled growth in vitro [26, 101]. This suggests a tumor suppressor role for CaSR. Bhagavathula and colleagues have provided evidence that CaSRmediated stimulation of E-cadherin signaling is disturbed in colon carcinoma cells with low or absent CaSR expression, resulting in the inability to generate strong cell-cell adhesion and differentiation signals [102]. This reinforces the observation by Chakrabarty and colleagues who provided clear evidence that interfering with the CaSR-E-cadherin-catenin axis results in abnormal differentiation and/or malignant progression of colon epithelial cells [63]. In addition, several CaSR SNPs have been found to correlate with susceptibility to colon cancer and/or disease progression [95, 103-105].

In the context of breast and prostate cancers (also called hypercalcemic cancers), CaSR activation promotes cancer progression and may favor metastases by stimulating tumor secretion of PTHrP [106-109]. PTHrP is a peptide growth factor that binds the same receptor as $\mathrm{PTH}$, thereby activating bone turnover and, hence, contributing to the pathogenesis of cancers by promoting osteolytic bone destruction with release of bone-derived growth promoting factors. The local hypercalcemia generated through bone resorption further stimulates the CaSR, producing a vicious cycle [106, 108, 109]. In sharp contrast, Li et al. reported that activation of the CaSR by calcimimetics in metastatic prostate cancer cell lines promoted apoptotic cell death [56]. These differences may result from a modified downstream CaSR signaling network upon acquiring a metastatic phenotype, and future studies will be needed to clarify this issue. Recently, Huang and colleagues demonstrated that CaSR driven Rho signaling is an important regulator of cell proliferation in more tumorigenic prostate cancer cell lines [110].

In addition to regulating tumorigenesis, CaSR expression levels have been found useful for risk stratification. Although investigated in a rather small cohort, elevated CaSR expression in breast tumors was reported to correlate with the incidence of bone metastasis [111]. This information suggests that the level of CaSR expression should be considered as a biomarker for the potential involvement of bone metastasis in breast cancer.

In hyperplastic parathyroid cells, CaSR activation by the calcimimetic R-568 induces apoptotic cell death, suggesting that in this specific tissue the CaSR functions as a tumor suppressor [57]. In accordance with the latter, CaSR expression is decreased in both parathyroid adenoma and hyperplasia [112]. Patients with inactivating mutations in the CaSR, especially those homozygous for such mutations, are prone to develop parathyroid hyperplasia. In contrast, no CaSR mutations were found in parathyroid tumors, but it was shown that the untranslated exon $1 \mathrm{~A}$ is expressed to a lower extent as compared with normal parathyroid cells [26].

\subsection{Alzheimer's Disease (AD)}

$A D$ is characterized by a disturbance in calcium homeostasis in the brain, suggesting that dysregulation of CaSR signaling is likely to be involved in the development or progression of this disease. Indeed, Conley and colleagues identified a significant association between the length of a dinucleotide repeat within intron 4 (short versus long) of the CaSR and susceptibility to $A D$. It is noteworthy that this association was significant only for individuals without an APOE4 allele, a genotype considered to be an independent risk factor for the development of $A D[113$, $114]$. Furthermore, the authors provide evidence that $\beta$ amyloid peptides and apoE protein activate CaSR signaling in cell culture, enhancing intracellular calcium levels and further promoting dysregulation of calcium homeostasis and calcium-dependent $\beta$-amyloid aggregation. In a more detailed analysis, Chairini and colleagues showed that $\beta$-amyloid-dependent CaSR activation in astrocytes stimulates MAPK cascades and induces a massive release of nitric oxide, which either independently or through conversion to peroxynitrite damages neighboring neurons [115].

\subsection{Atherosclerosis}

Atherosclerosis is the primary cause of heart disease and stroke, and represents a major cause of the high cardiovascular mortality rate in patients with end-stage renal disease [116-118]. Vascular calcification is an active, regulated process similar to that of osteogenesis in bone. During this process, loss 
of CaSR expression in vascular smooth muscle cells leads to the acquisition of an osteoblast-like phenotype and contributes to the generation of calcified nodules [119-123]. Koleganova and colleagues demonstrated, using an in vivo rat model for interstitial fibrosis and microvascular disease of the heart in uremia, that this transdifferentiation could be significantly delayed by administration of the calcimimetic R-568, suggesting the involvement of the CaSR in this process [124].

\section{CaSR AS A THERAPEUTIC TARGET}

The observed dysregulation of CaSR expression in hyperparathyroidism, a very common endocrine disease, and the change in clinical presentation of the disease following therapeutic targeting of the CaSR, as initially reported by Silverberg and colleagues [125], stimulated the development of CaSR-targeted drugs. Pharmacological agents with different modes of action, including allosteric modulators and monoclonal antibodies, are currently in development.

\subsection{Positive Allosteric Modulators}

Currently, only one positive allosteric modulator of CaSR, cinacalcet (Mimpara $^{\circledR}$ in Europe; Sensipar ${ }^{\circledR}$ in the USA), has entered the drug market [126]. Cinacalcet is used to increase CaSR activation, resulting in reduced PTH secretion and calcium levels in blood. Cinacalcet is currently prescribed for the treatment of secondary hyperparathyroidism in patients on dialysis for end-stage renal disease, and the treatment of primary hyperparathyroidism in patients with parathyroid carcinoma [126]. In addition to the conditions for which cinacalcet has been approved, literature indicates that this drug could be useful for treating other forms of primary and secondary hyperparathyroidism, as well as phosphate-wasting disorders, and may provide benefits in both infants and adults [126].

Although not yet approved for retail markets, modulation of CaSR function by pharmacological agonists may have additional therapeutic potential for the treatment of disorders such as idiopathic generalized epilepsies due to rare missense CaSR variants [127]. CaSR agonists may be useful in treating hypertensive states characterized by an inappropriately elevated renin concentration, as well, and may constitute a new approach for the prevention and treatment of numerous kidney disorders, such as diabetic nephropathy, through the above-mentioned nephroprotective effects [85]. Furthermore, calcimimetics could be useful in bone marrow transplants for stimulating homing, lodging, and engraftment of transplanted hematopoietic stem cells and progenitor cells [86, 128]. In addition, it has been proposed that calcimimetics have the potential to be effective therapeutic agents for secretory diarrheas because of their ability to reduce cAMP-mediated fluid secretion by the colon in rats [129]. Since calcimimetics have been shown to reduce the parathyroid gland volume in rats, mice and humans [79, 80, 130, 131], these compounds may also be useful as antiproliferative drugs in other tissues.

\subsection{Negative Allosteric Modulators}

Negative allosteric modulators (or calcilytics) of the CaSR have been developed as therapeutics for increasing bone growth by decreasing CaSR activation at the parathyroid gland and, thereby, stimulating endogenous PTH secretion. Such negative allosteric compounds are being studied for their potential use as anabolic agents in the treatment of osteoporosis [132]. Recently, it was shown in an ovariectomized rat model of bone loss that daily oral administration of the calcilytic prodrug SB-423557 increased bone formation and bone strength without affecting parathyroid cell proliferation [133]. Moreover, in aged female rats, the ATF936 calcilytic drug induced increased bone formation and, in healthy humans, a single dose triggered peak PTH levels and was well-tolerated [134]. However, further clinical studies will be needed to validate the efficacy and safety of ATF936 in treating osteoporosis. In addition, calcilytics could be useful for correcting hypocalcemia resulting from increased sensitivity of the CaSR to extracellular calcium [135].

\subsection{Other Modulators}

A potential drawback of most of the currently developed positive and negative allosteric modulators of the CaSR is that they are not fully selective for this receptor, since several allosteric modulators have been shown to activate or inhibit the closely related GPRC6A receptor $[136,137]$. This receptor has recently been shown to mediate the response of cells to androgens in several tissues [138]. Thus, the non-selective modulation of GPRC6A signaling through allosteric modulators may cause several unwanted side-effects. Therefore, a new strategy should be undertaken to provide drugs exclusively targeting the CaSR. Recently, it was shown that the CaSR and GPRC6A share similar, but not identical, binding pockets at the level of the allosteric binding site within the 7TM [137], which may allow the development of novel allosteric modulators with improved selectivity. In addition to allosteric modulators of CaSR binding the 7TM, allosteric modulators targeting the ECD of the receptor could be developed [24]. Additionally, monoclonal antibodies that specifically bind to lobe 2 of the human CaSR VFT and activate or inhibit the CaSR response to calcium have been described [139] and could be of potential use in the treatment of diseases for which calcimimetics and calcilytics, respectively, have been indicated.

\subsection{Targeted Modulators}

Since the CaSR is expressed in a wide variety of tissues, the long-term use of CaSR modulators to treat diseases specific to one tissue may have unintended consequences in other tissues. Thus, the next refinement of CaSR-modulating drugs should include designs for tissue-specific delivery. As the CaSR can heterodimerize with other family C GPCRs [34, 35], 
one potential tissue-specific targeting strategy could include modulators with specificity for heterodimers expressed in particular tissues [140]. Further research determining the precise tissue distribution of unique CaSR heterodimers will be required.

\section{CONCLUDING REMARKS}

Over the past decade, the CaSR has been identified as a novel molecular player in the determination of cellular fate with a fundamental impact on proliferation, apoptosis and differentiation in a diverse array of tissues [2-10]. The CaSR coordinates these activities through regulation of a myriad of signaling pathways, including EGFR signaling, MAPK cascades and Ecadherin signaling $[3,36,37,47,50-52,62-64]$. However, few studies have assessed the cell- or tissue-specificity of the cascades activated by engagement of the CaSR or determined the particular roles of the signaling cascades, leaving considerable room for discovery in this field. Tissue-specific signaling appears to be driven by the differential expression of splice variants, the heterodimerization with additional GPCRs, tissue specific interacting partners, the use of differential promoters, and translational regulation by miRNAs $[3,15,16,18-20$, $34,36,37,81]$.

The use of selective CaSR drugs, together with antisense and conditional gene knock-out technology, will certainly be of benefit in further unraveling the role of CaSR in cellular fate. Recent reports clearly point to a role for the CaSR as a regulator of early development and as a guardian of the homeostatic balance between proliferation and differentiation in adults $[19,68,70,71$, $73,75,89,92]$. The identification of CaSR mutations that cause $\mathrm{FHH}$ and hypocalcemia [93-98], and the recent discoveries implicating the dysregulation of CaSR signaling in many other diseases [99, 113-115, 119-124], position the CaSR as a broad therapeutic target. Adverse side-effects will likely be a challenging issue in the putative use of CaSR-modulating agents for the treatment of such a broad range of tissuespecific diseases; therefore, future studies should focus on the development of CaSR-modulating drugs with a higher selectivity for the CaSR and specificity for the tissue of interest.

\section{ABBREVIATIONS}

5'UTR = 5' Untranslated region

AA $=$ Arachidonic acid

$\mathrm{AC} \quad=$ Adenylate cyclase

AD = Alzheimer's disease

BAF-155 = BRG1-associated factor 155

BATF = Basic leucine zipper transcription factor

$\mathrm{BCL} 11 \mathrm{~A}=\mathrm{B}$-cell lymphoma 11A

$\mathrm{Bcl}-2=\mathrm{B}$-cell lymphoma 2

cAMP $=$ Cyclic AMP

$\begin{array}{ll}\text { CaSR } & =\text { Calcium-sensing receptor } \\ \text { CNS } & =\text { Central nervous system } \\ \text { CPLA2 } & =\text { Cytosolic phospholipase A2 } \\ \text { DAG } & =\text { Diacylglycerol } \\ \text { ECD } & =\text { Extracellular domain } \\ \text { EGFR } & =\text { Epidermal growth factor receptor } \\ \text { Egr-1 } & =\text { Early growth response factor } 1 \\ \text { ERK } & =\text { Extracellular signal-regulated kinase } \\ \text { FHH } & =\text { Familial hypocalciuric hypercalcemia } \\ \text { GABA } & =\text { Type B v-aminobutyric acid receptor } \\ \text { GPCR } & =\text { G protein-coupled receptor } \\ \text { IP3 } & =\text { Inositol 1,4,5-trisphosphate } \\ \text { JNK } & =\text { Jun N-terminal Kinase } \\ \text { MAPK } & =\text { Mitogen-activated protein kinase } \\ \text { MEK } & =\text { MAPK kinase } \\ \text { mGluR } & =\text { Metabotropic glutamate receptor } \\ \text { miRNAs } & =\text { MicroRNAs } \\ \text { NF-KB } & =\text { Nuclear factor } \text { B } \\ \text { p53 } & =\text { Tumor protein } 53 \\ \text { PI3K } & =\text { Phosphatidylinositol 3-kinase } \\ \text { PKC } & =\text { Protein kinase C } \\ \text { PLC } & =\text { Phospholipase C } \\ \text { PNS } & =\text { Peripheral nervous system } \\ \text { PTH } & =\text { Parathyroid hormone } \\ \text { PTHrP } & =\text { PTH-related protein } \\ \text { SNP } & =\text { Single nucleotide polymorphism } \\ \text { TF } & =\text { Transcription factor } \\ \text { TM } & =\text { Transmembrane } \\ \text { TTF1 } & =\text { Thyroid transcription factor } 1 \\ \text { VFT } & =\text { Venus flytrap } \\ & \end{array}$

\section{CONFLICT OF INTEREST}

No conflict of interest to be disclosed.

\section{ACKNOWLEDGEMENTS}

The authors wish to thank Stefanie Mortier for technical assistance in preparing the manuscript. This work was supported by the Flemish Fund for Children with Cancer (Kinderkankerfonds).

\section{REFERENCES}

[1] Brown EM, Gamba G, Riccardi D, et al. Cloning and characterization of an extracellular $\mathrm{Ca}(2+)$-sensing receptor from bovine parathyroid. Nature 1993; 366: 575-80.

[2] Smajilovic S, Tfelt-Hansen J. Calcium acts as a first messenger through the calcium-sensing receptor in the cardiovascular system. Cardiovasc Res 2007; 75: 457-67. 
[3] Tfelt-Hansen J, Brown EM. The calcium-sensing receptor in normal physiology and pathophysiology: a review. Crit Rev Clin Lab Sci 2005; 42: 35-70.

[4] Olszak IT, Poznansky MC, Evans RH, et al. Extracellular calcium elicits a chemokinetic response from monocytes in vitro and in vivo. J Clin Invest 2000; 105: 1299-305.

[5] Molostvov G, Fletcher S, Bland R, Zehnder D. Extracellular calcium-sensing receptor mediated signalling is involved in human vascular smooth muscle cell proliferation and apoptosis. Cell Physiol Biochem 2008; 22: 413-22.

[6] Whitfield JF. The calcium-sensing receptor-A driver of colon cell differentiation. Curr Pharm Biotechnol 2009; 10: 311-6.

[7] Huang C, Sindic A, Hill CE, et al. Interaction of the $\mathrm{Ca2+-}$ sensing receptor with the inwardly rectifying potassium channels Kir4.1 and Kir4.2 results in inhibition of channel function. Am J Physiol Renal Physiol 2007; 292: F1073-81.

[8] Lin K-I, Chattopadhyay N, Bai M, et al. Elevated Extracellular Calcium Can Prevent Apoptosis via the Calcium-Sensing Receptor. Biochem Biophys Res Commun 1998; 249: 32531.

[9] Hurtel-Lemaire AS, Mentaverri R, Caudrillier A, et al. The calcium-sensing receptor is involved in strontium ranelateinduced osteoclast apoptosis. New insights into the associated signaling pathways. J Biol Chem 2009; 284: 57584.

[10] Diez-Fraile A, Mussche S, Vanden Berghe T, Espeel M, Vandenabeele P, D'Herde KG. Expression of calciumsensing receptor in quail granulosa explants: a key to survival during folliculogenesis. Anat Rec 2010; 293: 890-9.

[11] Bräuner-Osborne $H$, Wellendorph $P$, Jensen AA. Structure, pharmacology and therapeutic prospects of family C Gprotein coupled receptors. Curr Drug Targets 2007; 8: 16984.

[12] Hofer AM, Brown EM. Extracellular calcium sensing and signalling. Nat Rev Mol Cell Biol 2003; 4: 530-8.

[13] Ray K, Clapp P, Goldsmith PK, Spiegel AM. Identification of the sites of $\mathrm{N}$-linked glycosylation on the human calcium receptor and assessment of their role in cell surface expression and signal transduction. J Biol Chem 1998; 273: 34558-67.

[14] Bai M, Quinn S, Trivedi S, et al. Expression and characterization of inactivating and activating mutations in the human Ca2+o-sensing receptor. J Biol Chem 1996; 271: 19537-45.

[15] Suzuki K, Lavaroni S, Mori A, et al. Thyroid transcription factor 1 is calcium modulated and coordinately regulates genes involved in calcium homeostasis in $\mathrm{C}$ cells. Mol Cell Biol 1998; 18: 7410-22.

[16] Abukawa $\mathrm{H}$, Mano $\mathrm{H}$, Arakawa $\mathrm{T}$, Hakeda $\mathrm{Y}$, Kimura $\mathrm{H}$, Kumegawa M. Tissue specific expression and differential regulation by 1alpha,25-dihydroxyvitamin D3 of the calciumsensing receptor (CaSR) gene in rat kidney, intestine, and calvaria. Cytotechnology 2001; 35: 81-6.

[17] Oda Y, Tu CL, Pillai S, Bikle DD. The calcium sensing receptor and its alternatively spliced form in keratinocyte differentiation. J Biol Chem 1998; 273: 23344-52.

[18] Rodriguez L, Tu C, Cheng Z, et al. Expression and functional assessment of an alternatively spliced extracellular $\mathrm{Ca} 2+-$ sensing receptor in growth plate chondrocytes. Endocrinology 2005; 146: 5294-303.

[19] Oda Y, Tu CL, Chang W, et al. The calcium sensing receptor and its alternatively spliced form in murine epidermal differentiation. J Biol Chem 2000; 275: 1183-90.

[20] Bradbury RA, Sunn KL, Crossley M, et al. Expression of the parathyroid $\mathrm{Ca}(2+)$-sensing receptor in cytotrophoblasts from human term placenta. J Endocrinol 1998; 156: 425-30.

[21] Tsai-Morris CH, Buczko E, Wang W, Dufau ML. Intronic nature of the rat luteinizing hormone receptor gene defines a soluble receptor subspecies with hormone binding activity. $J$ Biol Chem 1990; 265: 19385-8.

[22] Wang Y, Awumey EK, Chatterjee PK, et al. Molecular cloning and characterization of a rat sensory nerve $\mathrm{Ca} 2+-$-sensing receptor. Am J Physiol Cell Physiol 2003; 285: C64-75.

[23] Chikatsu N, Fukumoto S, Takeuchi $Y$, et al. Cloning and characterization of two promoters for the human calcium- sensing receptor (CaSR) and changes of CaSR expression in parathyroid adenomas. J Biol Chem 2000; 275: 7553-7.

[24] Jensen AA, Brauner-Osborne H. Allosteric modulation of the calcium-sensing receptor. Curr Neuropharmacol 2007; 5: 180-6.

[25] Hu J. Allosteric modulators of the human calcium-sensing receptor: structures, sites of action, and therapeutic potentials. Endocr Metab Immune Disord Drug Targets 2008; 8: 192-7.

[26] Saidak Z, Mentaverri R, Brown EM. The Role of the CalciumSensing Receptor in the Development and Progression of Cancer. Endocr Rev 2009; 30: 178-95.

[27] Conigrave AD, Quinn SJ, Brown EM. L-amino acid sensing by the extracellular $\mathrm{Ca} 2+-$-sensing receptor. Proc Natl Acad Sci USA 2000; 97: 4814-9.

[28] Zhang Z, Qiu W, Quinn SJ, Conigrave AD, Brown EM, Bai M. Three adjacent serines in the extracellular domains of the $\mathrm{CaR}$ are required for $\mathrm{L}$-amino acid-mediated potentiation of receptor function. J Biol Chem 2002; 277: 33727-35.

[29] Mun HC, Culverston EL, Franks AH, Collyer CA, Clifton-Bligh RJ, Conigrave AD. A double mutation in the extracellular $\mathrm{Ca} 2+-$ sensing receptor's venus flytrap domain that selectively disables L-amino acid sensing. J Biol Chem 2005; 280: 29067-72.

[30] Nemeth EF, Steffey ME, Hammerland LG, et al. Calcimimetics with potent and selective activity on the parathyroid calcium receptor. Proc Natl Acad Sci USA 1998; 95: 4040-5.

[31] Bai M. Structure-function relationship of the extracellular calcium-sensing receptor. Cell Calcium 2004; 35: 197-207.

[32] Bai M, Trivedi S, Kifor O, Quinn SJ, Brown EM. Intermolecular interactions between dimeric calcium-sensing receptor monomers are important for its normal function. Proc Natl Acad Sci USA 1999; 96: 2834-9.

[33] Brock C, Oueslati N, Soler S, Boudier L, Rondard P, Pin JP. Activation of a dimeric metabotropic glutamate receptor by intersubunit rearrangement. J Biol Chem 2007; 282: 330008.

[34] Gama L, Wilt SG, Breitwieser GE. Heterodimerization of calcium sensing receptors with metabotropic glutamate receptors in neurons. J Biol Chem 2001; 276: 39053-9.

[35] Chang W, Tu C, Cheng Z, et al. Complex formation with the Type B gamma-aminobutyric acid receptor affects the expression and signal transduction of the extracellular calcium-sensing receptor. Studies with HEK-293 cells and neurons. J Biol Chem 2007; 282: 25030-40.

[36] Yano S, Macleod RJ, Chattopadhyay N, et al. Calciumsensing receptor activation stimulates parathyroid hormonerelated protein secretion in prostate cancer cells: role of epidermal growth factor receptor transactivation. Bone 2004; 35: 664-72.

[37] El Hiani Y, Lehen'kyi V, Ouadid-Ahidouch H, Ahidouch A. Activation of the calcium-sensing receptor by high calcium induced breast cancer cell proliferation and TRPC1 cation channel over-expression potentially through EGFR pathways. Arch Biochem Biophys 2009; 486: 58-63.

[38] Zhang M, Breitwieser GE. High affinity interaction with filamin A protects against calcium-sensing receptor degradation. $J$ Biol Chem 2005; 280: 11140-6.

[39] Hjalm G, MacLeod RJ, Kifor O, Chattopadhyay N, Brown EM. Filamin-A binds to the carboxyl-terminal tail of the calcium-sensing receptor, an interaction that participates in CaR-mediated activation of mitogen-activated protein kinase. J Biol Chem 2001; 276: 34880-7.

[40] Pi M, Spurney RF, Tu Q, Hinson T, Quarles LD. Calciumsensing receptor activation of rho involves filamin and rhoguanine nucleotide exchange factor. Endocrinology 2002; 143: $3830-8$.

[41] Sampson LJ, Leyland ML, Dart C. Direct interaction between the actin-binding protein filamin-A and the inwardly rectifying potassium channel, Kir2.1. J Biol Chem 2003; 278: 4198897.

[42] Huang Y, Niwa J, Sobue G, Breitwieser GE. Calcium-sensing receptor ubiquitination and degradation mediated by the E3 ubiquitin ligase dorfin. J Biol Chem 2006; 281: 11610-7. 
[43] Kifor O, Kifor I, Moore FD, Jr., Butters RR, Jr., Brown EM. mCalpain colocalizes with the calcium-sensing receptor $(\mathrm{CaR})$ in caveolae in parathyroid cells and participates in degradation of the CaR. J Biol Chem 2003; 278: 31167-76.

[44] Gama L, Baxendale-Cox LM, Breitwieser GE. Ca2+-sensing receptors in intestinal epithelium. Am J Physiol 1997; 273: C1168-75.

[45] Bai M, Trivedi S, Lane CR, Yang Y, Quinn SJ, Brown EM. Protein kinase $\mathrm{C}$ phosphorylation of threonine at position 888 in $\mathrm{Ca} 2+0$-sensing receptor $(\mathrm{CaR})$ inhibits coupling to $\mathrm{Ca} 2+$ store release. J Biol Chem 1998; 273: 21267-75.

[46] Handlogten ME, Huang C, Shiraishi N, Awata H, Miller RT. The Ca2+-sensing receptor activates cytosolic phospholipase A2 via a Gqalpha -dependent ERKindependent pathway. J Biol Chem 2001; 276: 13941-8.

[47] Kifor O, MacLeod RJ, Diaz R, et al. Regulation of MAP kinase by calcium-sensing receptor in bovine parathyroid and CaR-transfected HEK293 cells. Am J Physiol Renal Physiol 2001; 280: F291-302.

[48] Hobson SA, McNeil SE, Lee F, Rodland KD. Signal transduction mechanisms linking increased extracellular calcium to proliferation in ovarian surface epithelial cells. Exp Cell Res 2000; 258: 1-11.

[49] Hobson SA, Wright J, Lee F, McNeil SE, Bilderback T, Rodland KD. Activation of the MAP kinase cascade by exogenous calcium-sensing receptor. Mol Cell Endocrinol 2003; 200: 189-98.

[50] Corbetta S, Lania A, Filopanti M, Vicentini L, Ballare E, Spada A. Mitogen-activated protein kinase cascade in human normal and tumoral parathyroid cells. J Clin Endocrinol Metab 2002; 87: 2201-5.

[51] Schaeffer HJ, Weber MJ. Mitogen-activated protein kinases: specific messages from ubiquitous messengers. Mol Cell Biol 1999; 19: 2435-44.

[52] Cobb MH. MAP kinase pathways. Prog Biophys Mol Biol 1999; 71: 479-500.

[53] Chattopadhyay N, Yano S, Tfelt-Hansen J, et al. Mitogenic action of calcium-sensing receptor on rat calvarial osteoblasts. Endocrinology 2004; 145: 3451-62.

[54] Sun YH, Liu MN, Li H, et al. Calcium-sensing receptor induces rat neonatal ventricular cardiomyocyte apoptosis. Biochem Biophys Res Commun 2006; 350: 942-8.

[55] Jiang CM, Han LP, Li HZ, et al. Calcium-sensing receptors induce apoptosis in cultured neonatal rat ventricular cardiomyocytes during simulated ischemia/reperfusion. Cell Biol Int 2008; 32: 792-800.

[56] Li H, Ruan G, Li Z, et al. The calcimimetic R-568 induces apoptotic cell death in prostate cancer cells. J Exp Clin Cancer Res 2009; 28: 100.

[57] Mizobuchi M, Ogata $\mathrm{H}$, Hatamura I, et al. Activation of calcium-sensing receptor accelerates apoptosis in hyperplastic parathyroid cells. Biochem Biophys Res Commun 2007; 362: 11-6.

[58] Zheng H, Liu J, Liu C, et al. Calcium-sensing receptor activating phosphorylation of PKCdelta translocation on mitochondria to induce cardiomyocyte apoptosis during ischemia/reperfusion. Mol Cell Biochem 2011; 358 (1-2): 335-43.

[59] Xing WJ, Kong FJ, Li GW, et al. Calcium-sensing receptors induce apoptosis during simulated ischaemia-reperfusion in Buffalo rat liver cells. Clin Exp Pharmacol Physiol 2011; 38: 605-12.

[60] Mentaverri R, Yano S, Chattopadhyay N, et al. The calcium sensing receptor is directly involved in both osteoclast differentiation and apoptosis. FASEB J 2006; 20: 2562-4.

[61] Dvorak MM, Siddiqua A, Ward DT, et al. Physiological changes in extracellular calcium concentration directly control osteoblast function in the absence of calciotropic hormones. Proc Natl Acad Sci USA 2004; 101: 5140-5.

[62] Tu CL, Chang W, Xie Z, Bikle DD. Inactivation of the calcium sensing receptor inhibits E-cadherin-mediated cell-cell adhesion and calcium-induced differentiation in human epidermal keratinocytes. J Biol Chem 2008; 283: 3519-28.

[63] Chakrabarty S, Radjendirane V, Appelman H, Varani J. Extracellular calcium and calcium sensing receptor function in human colon carcinomas: promotion of E-cadherin expression and suppression of beta-catenin/TCF activation. Cancer Res 2003; 63: 67-71.

[64] Tu CL, Chang W, Bikle DD. The calcium-sensing receptordependent regulation of cell-cell adhesion and keratinocyte differentiation requires Rho and filamin $\mathrm{A}$. J Invest Dermatol 2011; 131: 1119-28.

[65] Huang C, Handlogten ME, Miller RT. Parallel activation of phosphatidylinositol 4-kinase and phospholipase $\mathrm{C}$ by the extracellular calcium-sensing receptor. J Biol Chem 2002; 277: 20293-300.

[66] Mamillapalli R, Wysolmerski J. The calcium-sensing receptor couples to Galpha(s) and regulates PTHrP and ACTH secretion in pituitary cells. J Endocrinol 2010; 204: 287-97.

[67] Mamillapalli R, VanHouten J, Zawalich W, Wysolmerski J. Switching of G-protein usage by the calcium-sensing receptor reverses its effect on parathyroid hormone-related protein secretion in normal versus malignant breast cells. $\mathrm{J}$ Biol Chem 2008; 283: 24435-47.

[68] Riccardi D, Finney BA, Wilkinson WJ, Kemp PJ. Novel regulatory aspects of the extracellular Ca2+-sensing receptor, CaR. Pflugers Arch 2009; 458: 1007-22.

[69] Wandrup J, Kjer JJ, Thode J, Siggaard-Andersen O. The concentration of free calcium ions and total calcium in pregnancies at term. Scand J Clin Lab Invest 1982; 42: 2737.

[70] Vizard TN, O'Keeffe GW, Gutierrez H, Kos CH, Riccardi D, Davies AM. Regulation of axonal and dendritic growth by the extracellular calcium-sensing receptor. Nat Neurosci 2008; 11: 285-91.

[71] Finney BA, del Moral PM, Wilkinson WJ, et al. Regulation of mouse lung development by the extracellular calciumsensing receptor, CaR. J Physiol 2008; 586: 6007-19.

[72] Riccardi D, Park J, Lee WS, Gamba G, Brown EM, Hebert SC. Cloning and functional expression of a rat kidney extracellular calcium/polyvalent cation-sensing receptor. Proc Natl Acad Sci USA 1995; 92: 131-5.

[73] Chang W, Tu C, Chen TH, Bikle D, Shoback D. The extracellular calcium-sensing receptor (CaSR) is a critical modulator of skeletal development. Sci Signal 2008; 1: ra1.

[74] Kovacs CS, Ho-Pao CL, Hunzelman JL, et al. Regulation of murine fetal-placental calcium metabolism by the calciumsensing receptor. J Clin Invest 1998; 101: 2812-20.

[75] Bradbury RA, Cropley J, Kifor O, et al. Localization of the extracellular $\mathrm{Ca}(2+)$-sensing receptor in the human placenta. Placenta 2002; 23: 192-200.

[76] Hellman P, Hellman B, Juhlin $C$, et al. Regulation of proliferation in JEG-3 cells by a $500-\mathrm{kDa} \mathrm{Ca} 2+$ sensor and parathyroid hormone-related protein. Arch Biochem Biophys 1993; 307: 379-85.

[77] Chin J, Miller SC, Wada M, Nagano N, Nemeth EF, Fox J. Activation of the calcium receptor by a calcimimetic compound halts the progression of secondary hyperparathyroidism in uremic rats. J Am Soc Nephrol 2000; 11: 903-11.

[78] Mizobuchi M, Hatamura I, Ogata $\mathrm{H}$, et al. Calcimimetic compound upregulates decreased calcium-sensing receptor expression level in parathyroid glands of rats with chronic renal insufficiency. J Am Soc Nephrol 2004; 15: 2579-87.

[79] Wada M, Furuya Y, Sakiyama J, et al. The calcimimetic compound NPS R-568 suppresses parathyroid cell proliferation in rats with renal insufficiency. Control of parathyroid cell growth via a calcium receptor. J Clin Invest 1997; 100: 2977-83.

[80] Colloton M, Shatzen E, Miller G, et al. Cinacalcet $\mathrm{HCl}$ attenuates parathyroid hyperplasia in a rat model of secondary hyperparathyroidism. Kidney Int 2005; 67: 467-76.

[81] Wang $\mathrm{R}$, Xu C, Zhao $\mathrm{W}$, et al. Calcium and polyamine regulated calcium-sensing receptors in cardiac tissues. Eur $\mathrm{J}$ Biochem 2003; 270: 2680-8.

[82] Han L, Xu C, Jiang $\mathrm{C}$, et al. Effects of polyamines on apoptosis induced by simulated ischemia/reperfusion injury in cultured neonatal rat cardiomyocytes. Cell Biol Int 2007; 31: $1345-52$. 
[83] Zhang WH, Fu SB, Lu FH, et al. Involvement of calciumsensing receptor in ischemia/reperfusion-induced apoptosis in rat cardiomyocytes. Biochem Biophys Res Commun 2006; 347: 872-81.

[84] Yan L, Zhu TB, Wang LS, et al. Inhibitory effect of hepatocyte growth factor on cardiomyocytes apoptosis is partly related to reduced calcium sensing receptor expression during a model of simulated ischemia/reperfusion. Mol Biol Rep 2011; 38: 2695-701.

[85] Oh J, Beckmann J, Bloch J, et al. Stimulation of the calciumsensing receptor stabilizes the podocyte cytoskeleton, improves cell survival, and reduces toxin-induced glomerulosclerosis. Kidney Int 2011; 80: 483-92

[86] Lam BS, Cunningham C, Adams GB. Pharmacologic modulation of the calcium-sensing receptor enhances hematopoietic stem cell lodgment in the adult bone marrow. Blood 2011; 117: 1167-75.

[87] McNeil L, Hobson S, Nipper V, Rodland KD. Functional calcium-sensing receptor expression in ovarian surface epithelial cells. Am J Obstet Gynecol 1998; 178: 305-13.

[88] De Santis T, Casavola V, Reshkin SJ, et al. The extracellular calcium-sensing receptor is expressed in the cumulus-oocyte complex in mammals and modulates oocyte meiotic maturation. Reproduction 2009; 138: 439-52.

[89] Geibel JP, Hebert SC. The functions and roles of the extracellular $\mathrm{Ca} 2+$-sensing receptor along the gastrointestinal tract. Annu Rev Physiol 2009; 71: 205-17.

[90] Hennings $\mathrm{H}$, Holbrook KA. Calcium regulation of cell-cell contact and differentiation of epidermal cells in culture. An ultrastructural study. Exp Cell Res 1983; 143: 127-42.

[91] Hennings H, Holbrook KA, Yuspa SH. Factors influencing calcium-induced terminal differentiation in cultured mouse epidermal cells. J Cell Physiol 1983; 116: 265-81.

[92] Tu CL, Oda Y, Komuves L, Bikle DD. The role of the calciumsensing receptor in epidermal differentiation. Cell Calcium 2004; 35: 265-73.

[93] Egbuna OI, Brown EM. Hypercalcaemic and hypocalcaemic conditions due to calcium-sensing receptor mutations. Best Pract Res Clin Rheumatol 2008; 22: 129-48.

[94] Vezzoli G, Scillitani A, Corbetta S, et al. Polymorphisms at the regulatory regions of the CASR gene influence stone risk in primary hyperparathyroidism. Eur J Endocrinol 2011; 164: 421-7.

[95] Jenab M, McKay J, Bueno-de-Mesquita HB, et al. Vitamin D receptor and calcium sensing receptor polymorphisms and the risk of colorectal cancer in European populations. Cancer Epidemiol Biomarkers Prev 2009; 18: 2485-91.

[96] Scillitani A, Guarnieri V, Battista C, et al. Primary hyperparathyroidism and the presence of kidney stones are associated with different haplotypes of the calcium-sensing receptor. J Clin Endocrinol Metab 2007; 92: 277-83.

[97] Charrie A, Chikh K, Peix JL, et al. Calcium-sensing receptor autoantibodies in primary hyperparathyroidism. Clin Chim Acta 2009; 406: 94-7.

[98] $\mathrm{Li} \mathrm{Y}$, Song $\mathrm{YH}$, Rais $\mathrm{N}$, et al. Autoantibodies to the extracellular domain of the calcium sensing receptor in patients with acquired hypoparathyroidism. J Clin Invest 1996; 97: 910-4.

[99] Chakravarti B, Dwivedi SKD, Mithal A, Chattopadhyay N. Calcium-sensing receptor in cancer: good cop or bad cop? Endocrine 2009; 35: 271-84.

[100] de Santa Barbara P, van den Brink GR, Roberts DJ. Development and differentiation of the intestinal epithelium. Cell Mol Life Sci 2003; 60: 1322-32.

[101] Dame MK, Bhagavathula N, Mankey C, et al. Human colon tissue in organ culture: preservation of normal and neoplastic characteristics. In Vitro Cell Dev Biol Anim 2010; 46: 114-22.

[102] Bhagavathula N, Hanosh AW, Nerusu KC, Appelman H, Chakrabarty S, Varani J. Regulation of E-cadherin and betacatenin by $\mathrm{Ca} 2+$ in colon carcinoma is dependent on calcium-sensing receptor expression and function. Int $\mathrm{J}$ Cancer 2007; 121: 1455-62.

[103] Jacobs ET, Martinez ME, Campbell PT, et al. Genetic variation in the retinoid $X$ receptor and calcium-sensing receptor and risk of colorectal cancer in the Colon Cancer Family Registry. Carcinogenesis 2010; 31: 1412-6.

[104] Bacsi K, Hitre E, Kosa JP, et al. Effects of the lactase 13910 $\mathrm{C} / \mathrm{T}$ and calcium-sensor receptor A986S G/T gene polymorphisms on the incidence and recurrence of colorectal cancer in Hungarian population. BMC Cancer 2008; 8: 317.

[105] Dong LM, Ulrich CM, Hsu L, et al. Genetic variation in calcium-sensing receptor and risk for colon cancer. Cancer Epidemiol Biomarkers Prev 2008; 17: 2755-65.

[106] Guise TA, Kozlow WM, Heras-Herzig A, Padalecki SS, Yin JJ, Chirgwin JM. Molecular mechanisms of breast cancer metastases to bone. Clin Breast Cancer 2005; 5 Suppl: S4653.

[107] Lorch G, Viatchenko-Karpinski S, Ho HT, et al. The calciumsensing receptor is necessary for the rapid development of hypercalcemia in human lung squamous cell carcinoma. Neoplasia 2011; 13: 428-38.

[108] Sanders JL, Chattopadhyay N, Kifor O, Yamaguchi T, Brown EM. $\mathrm{Ca}(2+)$-sensing receptor expression and $\mathrm{PTHrP}$ secretion in PC-3 human prostate cancer cells. Am J Physiol Endocrinol Metab 2001; 281: E1267-74.

[109] Sanders JL, Chattopadhyay N, Kifor O, Yamaguchi T, Butters RR, Brown EM. Extracellular calcium-sensing receptor expression and its potential role in regulating parathyroid hormone-related peptide secretion in human breast cancer cell lines. Endocrinology 2000; 141: 4357-64.

[110] Huang C, Liu S, Miller RT. Role of p115RhoGEF in the regulation of extracellular $\mathrm{Ca}(2+)$-induced choline kinase activation and prostate cancer cell proliferation. Int $\mathrm{J}$ Cancer 2011; 128: 2833-42.

[111] Mihai R, Stevens J, McKinney C, Ibrahim NB. Expression of the calcium receptor in human breast cancer--a potential new marker predicting the risk of bone metastases. Eur J Surg Oncol 2006; 32: 511-5.

[112] Rodland KD. The role of the calcium-sensing receptor in cancer. Cell Calcium 2004; 35: 291-5.

[113] Conley YP, Mukherjee A, Kammerer C, et al. Evidence Supporting a Role for the Calcium-Sensing Receptor in Alzheimer Disease. Am J Med Genet B: Neuropsychiatr Genet 2009; 150B: 703-9.

[114] Selkoe DJ, Podlisny MB. Deciphering the genetic basis of Alzheimer's disease. Annu Rev Genomics Hum Genet 2002; 3: 67-99.

[115] Chiarini A, Dal Pra I, Marconi M, Chakravarthy B, Whitfield JF, Armato U. Calcium-sensing receptor (CaSR) in human brain's pathophysiology: roles in late-onset Alzheimer's disease (LOAD). Curr Pharm Biotechnol 2009; 10: 317-26.

[116] Lusis AJ. Atherosclerosis. Nature 2000; 407: 233-41.

[117] Giachelli CM. Vascular calcification mechanisms. J Am Soc Nephrol 2004; 15: 2959-64.

[118] Moe SM, Chen NX. Pathophysiology of vascular calcification in chronic kidney disease. Circ Res 2004; 95: 560-7.

[119] Bostrom K, Watson KE, Horn S, Wortham C, Herman IM, Demer LL. Bone morphogenetic protein expression in human atherosclerotic lesions. J Clin Invest 1993; 91: 1800-9.

[120] Shioi A, Nishizawa Y, Jono S, Koyama H, Hosoi M, Morii H. Beta-glycerophosphate accelerates calcification in cultured bovine vascular smooth muscle cells. Arterioscler Thromb Vasc Biol 1995; 15: 2003-9.

[121] Tyson KL, Reynolds JL, McNair R, Zhang Q, Weissberg PL, Shanahan CM. Osteo/chondrocytic transcription factors and their target genes exhibit distinct patterns of expression in human arterial calcification. Arterioscler Thromb Vasc Biol 2003; 23: 489-94.

[122] Alam MU, Kirton JP, Wilkinson FL, et al. Calcification is associated with loss of functional calcium-sensing receptor in vascular smooth muscle cells. Cardiovasc Res 2009; 81: 260-8.

[123] Molostvov G, James S, Fletcher S, et al. Extracellular calcium-sensing receptor is functionally expressed in human artery. Am J Physiol Renal Physiol 2007; 293: F946-55.

[124] Koleganova N, Piecha G, Ritz E, et al. Interstitial fibrosis and microvascular disease of the heart in uremia: amelioration by a calcimimetic. Lab Invest 2009; 89: 520-30. 
[125] Silverberg SJ, Bone HG, 3rd, Marriott TB, et al. Short-term inhibition of parathyroid hormone secretion by a calciumreceptor agonist in patients with primary hyperparathyroidism. N Engl J Med 1997; 337: 1506-10.

[126] Brown EM. Clinical utility of calcimimetics targeting the extracellular calcium-sensing receptor (CaSR). Biochem Pharmacol 2010; 80: 297-307.

[127] Maillard MP, Tedjani A, Perregaux C, Burnier M. Calciumsensing receptors modulate renin release in vivo and in vitro in the rat. J Hypertens 2009; 27: 1980-7.

[128] Adams GB, Chabner KT, Alley IR, et al. Stem cell engraftment at the endosteal niche is specified by the calcium-sensing receptor. Nature 2006; 439: 599-603.

[129] Geibel J, Sritharan K, Geibel R, et al. Calcium-sensing receptor abrogates secretagogue- induced increases in intestinal net fluid secretion by enhancing cyclic nucleotide destruction. Proc Natl Acad Sci USA 2006; 103: 9390-7.

[130] Imanishi $\mathrm{Y}$, Kawata $\mathrm{T}$, Kenko $\mathrm{T}$, et al. Cinacalcet $\mathrm{HCl}$ Suppresses Cyclin D1 Oncogene-Derived Parathyroid Cell Proliferation in a Murine Model for Primary Hyperparathyroidism. Calcif Tissue Int 2011; 89: 29-35.

[131] Komaba $H$, Nakanishi S, Fujimori A, et al. Cinacalcet effectively reduces parathyroid hormone secretion and gland volume regardless of pretreatment gland size in patients with secondary hyperparathyroidism. Clin J Am Soc Nephrol 2010; 5: 2305-14.

[132] Trivedi R, Mithal A, Chattopadhyay N. Anabolics in osteoporosis: the emerging therapeutic tool. Curr Mol Med 2010; 10: 14-28.
[133] Kumar S, Matheny CJ, Hoffman SJ, et al. An orally active calcium-sensing receptor antagonist that transiently increases plasma concentrations of PTH and stimulates bone formation. Bone 2010; 46: 534-42.

[134] John MR, Widler L, Gamse R, et al. ATF936, a novel oral calcilytic, increases bone mineral density in rats and transiently releases parathyroid hormone in humans. Bone 2011; 49: 233-41.

[135] Brown EM. Clinical lessons from the calcium-sensing receptor. Nat Clin Pract Endocrinol Metab 2007; 3: 122-33.

[136] Pi M, Faber P, Ekema G, et al. Identification of a novel extracellular cation-sensing G-protein-coupled receptor. J Biol Chem 2005; 280: 40201-9.

[137] Faure H, Gorojankina T, Rice N, et al. Molecular determinants of non-competitive antagonist binding to the mouse GPRC6A receptor. Cell Calcium 2009; 46: 323-32.

[138] Pi M, Parrill AL, Quarles LD. GPRC6A mediates the nongenomic effects of steroids. J Biol Chem 2010; 285: 3995364.

[139] Hu J, Reyes-Cruz G, Goldsmith PK, Gantt NM, Miller JL, Spiegel AM. Functional effects of monoclonal antibodies to the purified amino-terminal extracellular domain of the human $\mathrm{Ca}(2+)$ receptor. J Bone Miner Res 2007; 22: 601-8.

[140] van Rijn RM, Whistler JL, Waldhoer M. Opioid-receptorheteromer-specific trafficking and pharmacology. Curr Opin Pharmacol 2010; 10: 73-9. 